\title{
Insulin resistance and inflammation markers in myocardial infarction
}

\author{
This article was published in the following Dove Press journal: \\ Journal of Inflammation Research \\ 15 June 2013 \\ Number of times this article has been viewed
}

\section{Olga Gruzdeva \\ Evgenya Uchasova \\ Yulia Dyleva \\ Ekaterina Belik \\ Ekaterina Shurygina \\ Olga Barbarash}

Research Institute for Complex Issues of Cardiovascular Diseases, Kemerovo, Russia

Correspondence: Evgenya Uchasova Research Institute for Complex Issues of Cardiovascular Diseases, 6 Sosnovy Blvd, Kemerovo 650002, Russia

Tel +7 3842640553

Email evg.uchasova@yandex.ru
Background: Insulin resistance (IR) is known to be characteristic of type 2 diabetes mellitus, and is regarded as an important mechanism in disease pathogenesis. One of the key pathogenetic mechanisms of IR progression is impaired free fatty acid (FFA) metabolism. Plasminogenactivator inhibitor 1 (PAI-1) and key inflammation markers, ie, interleukin 6 (IL-6) and C-reactive protein (CRP), also play a role.

Purpose: To assess the changing levels of the metabolic proinflammation IR markers IL-6, CRP and PAI-1 and their association with the presence or absence of type 2 diabetes mellitus in myocardial infarction (MI) patients during their hospital stay.

Methods: The patients were divided into two groups: group 1 included 95 nondiabetic MI patients, and group 2 enrolled 40 diabetic MI patients. The control group consisted of 30 sexand age-matched volunteers. Serum IL-6 and CRP levels as well as FFA, glucose, C-peptide, insulin, and plasma PAI-1 concentrations were measured at days 1 and 12 from MI onset.

Results: At day 1, there was an increase in glucose concentrations, which remained high in both groups by day 12 but was much higher in the diabetic patients. Basal insulin and C-peptide levels did not differ significantly from those in the control group. The quantitative insulin sensitivitycheck index in both groups was significantly different from that in controls. FFA concentrations at day 1 in both diabetic and nondiabetic patients increased; by day 12, they had decreased but were still higher than the controls. CRP and IL-6 levels at day 1 were higher in all the patients, but diabetic patients had the highest levels; by day 12 , the levels were lower but still 2.4-fold (IL-6) and 12.5-fold (CRP) higher than those in the control group.

Conclusion: This study showed that MI is accompanied both by activated inflammatory response and IR. Strong correlations between IL-6 and FFA concentrations demonstrate that nonspecific inflammation factors are involved in IR development in MI patients. Consequently, these inflammatory cytokines might cause the development of IR.

Keywords: insulin resistance, myocardial infarction, inflammation, type 2 diabetes mellitus

\section{Introduction}

Insulin resistance (IR) is known to be a characteristic feature of type 2 diabetes mellitus (T2DM), and is traditionally regarded as an important stage of its pathogenesis: IR in general and diabetic populations is associated with cardiovascular risk factors including hyperglycemia, dyslipoproteinemia, arterial hypertension, obesity, thrombosis, and smoking. ${ }^{1,2}$

Large clinical trials showed that IR was a predictor of such cardiovascular events as ischemic heart disease and myocardial infarction (MI). ${ }^{3,4}$ Additionally, it was established that the course of MI as a separate disease is accompanied by IR development 
and that the pathogenetic mechanisms are unclear. Medical literature has, among others, the following possible reasons for IR development: activation of local inflammation in the area of atherosclerotic lesion and infarct site with enhanced expression of proinflammatory cytokines (IL-6) and acutephase proteins, including C-reactive protein (CRP), as their key representative. ${ }^{5}$ An important role of increased CRP levels not only as an MI predictor and a marker of adverse outcome but also as a precursor of IR development was established earlier. ${ }^{6}$ High CRP levels are thought to result in a change in insulin-action regulation at the cellular level, which could lead to IR. ${ }^{7}$

Among proinflammatory cytokines contributing to IR development, the role of interleukin (IL)-6, which has autocrine and paracrine properties and is involved in insulin reception and free fatty acid (FFA) metabolism regulation, has been extensively studied. The increase in FFA concentrations in myocardial ischemia could also lead to a reduced sensitivity to insulin in the peripheral tissues. ${ }^{8,9}$ Moreover, previous experimental studies demonstrated that IL-6 could induce plasminogen-activator inhibitor (PAI)-1 production. Its activity increase is regarded both as a risk factor for coronary atherothrombosis and $\mathrm{MI}$ and as a trigger for IR development. ${ }^{10}$ PAI-1 is known to modulate insulin signaling in fibroblasts, preventing vitronectin binding to $\alpha_{\mathrm{v}} \beta_{3}$ receptors, which in turn decreases insulin-induced protein kinase B phosphorylation. ${ }^{11}$

According to Juhan-Vague et al, obese patients with hyperinsulinemia and a genotype associated with the increased PAI-1 transcription had a high risk of MI. ${ }^{12}$ Thus, an analysis of the medical literature allows the suggestion that proinflammatory factors could be involved in IR development in acute coronary events. The detection of a possible association between metabolic changes, indicators, and nonspecific inflammation markers in MI patients, including those with T2DM, can play a role in the choice of treatment strategy in terms of risk stratification in this category of patients.

This study was aimed at assessing the changing levels of the metabolic proinflammation IR markers IL-6, CRP and PAI-1, and their association with presence or absence of T2DM in MI patients during their hospital stay.

\section{Materials and methods} Study subjects and design

A total of $155 \mathrm{MI}$ patients (95 males and 60 females), mean age $65 \pm 4.5$ years, and 30 sex- and age-matched volunteers (the control group) with no cardiovascular or endocrine diseases were enrolled in the study. The patients were divided into two groups: group I comprised 95 nondiabetic MI patients, and group 2 enrolled 60 diabetic MI patients. The mean T2DM duration was, on average, $6.4 \pm 1.5$ years. The groups were sex- and age-matched and had similar risk factors for ischemic heart disease, concurrent conditions, and MI complication rate.

The main demographic characteristics of the study patients are summarized in Table 1. The patient groups were similar in age, sex, main risk factors of ischemic heart disease, comorbidities, and coronary event incidence (Table 1). The study excluded patients older than 75 years and/or with clinically significant concurrent conditions (autoimmune diseases, thyroid gland, or adrenal gland diseases). However, there were more obese patients among those with T2DM compared to nondiabetic patients, according to body mass index (BMI) levels: 29.65 (26.85-34.55) kg/m² vs $25.5(23.2-30.1) \mathrm{kg} / \mathrm{m}^{2}$.

Acute MI was diagnosed according to the 2007 Russian National Cardiology Society guidelines based on clinical, electrocardiographic, echocardiographic, and biochemical signs of the disease. The inclusion criteria were chest pain refractory to nitroglycerin, myocardial ischemia, and necrosis signs (ST-segment elevation and/or new pathologic Q waves on the electrocardiogram, elevated cardiac enzymes: $\mathrm{MB}$ fraction of creatine kinase $[\mathrm{CK} \mathrm{MB}]$ and troponin $\mathrm{T}$ ).

Table I Initial clinical and anamnestic characteristics of patients

\begin{tabular}{|c|c|c|}
\hline Variable & $\begin{array}{l}\text { Patients with MI } \\
\text { without type } 2 \\
\text { diabetes }(n=95)\end{array}$ & $\begin{array}{l}\text { Patients with } \\
\text { MI and type } 2 \\
\text { diabetes }(n=60)\end{array}$ \\
\hline Men, n (\%) & $69(73)$ & $18(30)$ \\
\hline Age, years, mean (range) & $6 \mathrm{I}(53-70)$ & $66.5(6 I-73.5)$ \\
\hline $\begin{array}{l}\text { Body mass index, } \\
\text { mean (range) }\end{array}$ & $25.5(23.2-30.1)$ & $29.65(26.85-34.55)$ \\
\hline Body weight kg, n (\%) & $53(56)$ & $51(85)$ \\
\hline $\begin{array}{l}\text { Arterial hypertension, } \\
\mathrm{n}(\%)\end{array}$ & $72(76)$ & $51(85)$ \\
\hline $\begin{array}{l}\text { Hypercholesterolemia, } \\
\text { n (\%) }\end{array}$ & $40(37.4)$ & $27(45)$ \\
\hline Current smoking, n (\%) & $72(76)$ & $37(61.6)$ \\
\hline $\begin{array}{l}\text { Family history of IHD, } \\
\mathrm{n}(\%)\end{array}$ & $23(24)$ & $30(50)$ \\
\hline $\begin{array}{l}\text { Previous myocardial } \\
\text { infarction, } \mathrm{n}(\%)\end{array}$ & $15(15.7)$ & $15(25)$ \\
\hline Chronic bronchitis, n (\%) & $5(5.2)$ & 0 \\
\hline Ulcerous disease, n (\%) & $10(9.3)$ & $5(8.3)$ \\
\hline $\begin{array}{l}\text { Chronic kidney disease, } \\
\mathrm{n}(\%)\end{array}$ & $2(2.1)$ & I (I.6) \\
\hline $\begin{array}{l}\text { Anterior wall myocardial } \\
\text { infarction, } \mathrm{n}(\%)\end{array}$ & $45(42)$ & $9(15)$ \\
\hline Killip class I, n (\%) & $87(81.4)$ & $26(43.3)$ \\
\hline Killip class II-IV, n (\%) & $21(35)$ & $32(53.3)$ \\
\hline Death, n (\%) & I (0.9) & I (I.6) \\
\hline
\end{tabular}

Abbreviations: MI, myocardial infarction; IHD, ischemic heart disease. 
Peak CK MB and troponin T levels did not differ between the groups. Peak CK MB levels were 94.03 $\pm 17.9 \mathrm{U} / \mathrm{L}$ and $137.64 \pm 41.1 \mathrm{U} / \mathrm{L}$ in the diabetic and nondiabetic patients, respectively $(P=0.916)$; troponin $\mathrm{T}$ concentrations were $1.09 \pm 0.92 \mathrm{ng} / \mathrm{mL}$ and $0.71 \pm 0.41 \mathrm{ng} / \mathrm{mL}$ in the diabetic and nondiabetic patients, respectively $(P=0.564)$.

The exclusion criteria were age $>75$ years, clinically significant comorbidities (autoimmune diseases, thyroid or adrenal gland diseases), acute coronary syndrome as a complication of percutaneous coronary intervention, or coronary artery bypass surgery.

The patient groups had a similar incidence of major hospital coronary events (Table 1). Eighty percent of patients in both groups did not have any signs of acute heart failure, according to the Killip classification (1967) upon admission and during the hospital stay (Table 1); however, more than $50 \%$ of patients had arrhythmias and impaired conduction diagnosed according to the established criteria. ${ }^{13}$ The structure and function of the left ventricle did not differ between the groups. Mean left ventricular ejection fraction was $51.25 \% \pm 1.85 \%$ in the diabetic patients and $50.42 \% \pm 1.62 \%$ in those without T2DM $(P=0.598)$; mean left ventricular end-diastolic volume was $164.35 \pm 10.47 \mathrm{~mL}$ in the diabetic patients and $156.43 \pm 7.18 \mathrm{~mL}$ in the nondiabetic patients $(P=0.649)$; mean left ventricular end-systolic volume was $79.71 \pm 8.32 \mathrm{~mL}$ in the diabetic patients and $75.22 \pm 5.56$ in the nondiabetic patients $(P=0.702)$.

The groups were similar in the presence/type of coronary artery disease: coronary angiography showed multivessel (more than three vessels) hemodynamically significant coronary artery lesions in both groups $(76.5 \%$ in the diabetic patients and $62.5 \%$ in the nondiabetic patients $[P=0.857]$ ). T2DM compensation was evaluated based on glycated hemoglobin levels (T2DM was considered to be compensated in glycated hemoglobin $>7.5 \%$, according to the 2000 European Diabetes Policy Group criteria). Decompensated T2DM was diagnosed in eight (40\%) patients.

The study design was approved by the Institutional Review Board of the Research Institute for Complex Issues of Cardiovascular Diseases; all the individuals signed the informed consent before being enrolled in the study. Therapeutic interventions during the follow-up period are listed in Table 2.

\section{Assays}

Serum IL-6 concentrations were measured by enzyme-linked immunosorbent assay at days 1 and 12 from the MI onset using Life Technologies (Carlsbad, CA, USA) test-systems.
Table 2 Revascularization and drug therapy during follow-up

\begin{tabular}{lll}
\hline Therapy, n (\%) & $\begin{array}{l}\text { Patients with MI } \\
\text { without type 2 } \\
\text { diabetes }(\mathbf{n}=\mathbf{9 5})\end{array}$ & $\begin{array}{l}\text { Patients with } \\
\text { MI and type 2 } \\
\text { diabetes }(\mathbf{n = 6 0})\end{array}$ \\
\hline $\begin{array}{l}\text { B-blockers } \\
\text { Angiotensin-converting }\end{array}$ & $85(89.5)$ & 5 I (85) \\
enzyme & $782.1)$ & $5 I(85)$ \\
Calcium channel blocker & $66(69.5)$ & $39(65)$ \\
Diuretics & $40(42)$ & $39(60)$ \\
Nitrates & $83(87.4)$ & $31(51.6)$ \\
Aspirin & $94(87.8)$ & $55(91.6)$ \\
Heparin & $95(100)$ & $60(100)$ \\
Clopidogrel & $84(78.5)$ & $44(73.3)$ \\
Statins & $95(100)$ & $60(100)$ \\
\hline
\end{tabular}

Abbreviation: MI, myocardial infarction.

CRP, serum FFA, and glucose concentrations were measured at the same study time points using standard Thermo Fisher Scientific (Vantaa, Finland) test systems on a Konelab 30i biochemistry analyzer (Thermo Fisher Scientific Oy, Vantaa, Finland). C-peptide and insulin concentrations were measured by enzyme-linked immunosorbent assay with BioMedica (Waterloo, NSW, Australia) and Diagnostic Systems Laboratories (Webster, TX, USA) lab kits, respectively. Plasma PAI-1 concentrations were assessed with standard Technoclone (Vienna, Austria) test systems. Additionally, all the patients had their postprandial glycemia, insulin, and C-peptide concentrations measured 2 hours after a standard carbohydrate breakfast (75 g anhydrous glucose dissolved in 250-300 mL water to drink for 3-5 minutes on an empty stomach).

The IR level was estimated using a structural mathematical model incorporating fasting serum insulin and glucose measurement with the quantitative insulin sensitivity-check index (QUICKI) calculation. QUICKI $=1 /\left(\log \left[\mathrm{I}_{0}\right]+\log \right.$ $\left.\left[\mathrm{G}_{0}\right]\right)$, where $\mathrm{I}_{0}$ - basal insulinemia $(\mathrm{mg} / \mathrm{dL}), \mathrm{G}_{0}$ - basal glycemia ( $\mathrm{mME} / \mathrm{mL})$. According to Katz et al, a mean QUICKI value of $0.382 \pm 0.007$ correlates with normal tissue sensitivity to insulin, while QUICKI values of $0.331 \pm 0.010$ and $0.304 \pm 0.007$ correlate with moderate and severe IR. ${ }^{14}$

\section{Statistical analysis}

Statistical analysis was done using the nonparametric MannWhitney test for unpaired samples and the Wilcoxon test for paired samples. The results were presented as median and quartiles. $P$-values $<0.05$ were considered statistically significant. Spearman's correlation coefficient was calculated to analyze the correlations between the variables. The statistical analysis was performed using Statistica 6.0 (StatSoft, Tulsa, OK, USA). 


\section{Results}

The diabetic and nondiabetic MI patients were found to have a 1.5-fold and 1.9-fold increase (respectively) in blood glucose levels at day 1 compared to those in the control group (Table 3). The increase in basal glucose levels was still present at day 12 in both patient groups, but was more pronounced in the diabetic patients. Postprandial glucose concentrations were 2.6-fold increased in the individuals with MI and T2DM at day 12, while in the nondiabetic patients postprandial glucose levels decreased compared to the basal levels but did not reach those in the controls.

Unlike glucose concentrations, fasting serum insulin and C-peptide levels had a tendency towards increasing in both groups at days 1 and 12 after MI onset, but did not differ from those in the controls (Table 3). The change in postprandial levels of those parameters at day 12 was more significant. Indeed, postprandial insulin concentrations both in the diabetic and nondiabetic MI patients crept up in an almost similar way compared to the control and basal levels.

Despite the fact that the changes in glucose metabolism were less pronounced in the nondiabetic MI patients, the integral QUICKI of IR in both groups significantly differed from that in the controls. In the controls, the QUICKI value was $0.38 \pm 0.01$ and corresponded to the normal tissue sensitivity to insulin. In the group of nondiabetic patients, QUICKI values were $0.316 \pm 0.005$ and $0.319 \pm 0.005$ at days 1 and 12 , respectively, which were regarded as borderline values between severe and moderate IR. In diabetic MI patients, QUICKI values were $0.296 \pm 0.009$ and $0.300 \pm 0.005$, which according to Katz et al corresponded to severe IR. ${ }^{14}$

Analysis of FFA concentration changes in MI patients showed significant differences compared to the controls both at day 1 and at day 12 of the disease (Table 4). At day 1, FFA concentrations in both diabetic and nondiabetic MI patients were seven- and elevenfold higher than those in the controls, respectively. By day 12, the levels had decreased, but were still three- and 4.7-fold higher than those in the controls; thus, in patients with such comorbidity, these changes were more pronounced during the entire follow-up period.

PAI-1 concentrations were found to be increased in both groups, but at the same time at day 1 the diabetic MI patients had a 4.6-fold increase in PAI-1 levels compared to the controls (Table 4). These values were, on average, twofold higher than those in the nondiabetic patients. At day 12 from MI onset, PAI-1 concentrations significantly decreased in both groups; however, they did not reach the control levels.

Measurement of the key inflammation markers showed that at day 1, the whole study population had 3.6- and 
Table 4 Basal level of free fatty acids and type I plasminogen activator inhibitor, respectively at I and I2 days of the MI development

\begin{tabular}{|c|c|c|c|c|c|}
\hline \multirow[t]{2}{*}{ Variables } & \multirow[t]{2}{*}{ Control $(n=30)$} & \multicolumn{2}{|c|}{ Patients with MI $(n=95)$} & \multicolumn{2}{|c|}{$\begin{array}{l}\text { Patients with } M I \text { and type } 2 \text { diabetes } \\
\text { mellitus }(n=60)\end{array}$} \\
\hline & & I-st day & 12-th day & I-st day & 12-th day \\
\hline FFA, mmol/L & $0.20(0.15 ; 0.22)$ & $1.38(I .32 ; \mid .4 I)^{* \#}$ & $0.61(0.59 ; 0.68)^{* * \#}$ & $2.20(2.0 ; 2.32)^{*}$ & $0.90(0.86 ; 0.95)^{* *}$ \\
\hline PAl, pg/mL & $35.35(34.1 ; 37.1)$ & $86.1(84.3 ; 89.1)^{* \#}$ & $70.21(65.8 ; 76.3)^{* * \#}$ & $160.6(149.3 ; 178.3)^{*}$ & $103.3(96.5 ; \mid 14.3)^{* *}$ \\
\hline
\end{tabular}

Notes: *compared with control, $(P<0.05)$; **reliable differences in indicators I-st and I2-th day, $(P<0.05)$; ${ }^{*}$ reliable differences among patients with MI with type 2 diabetes and without type 2 diabetes mellitus, $(P<0.05)$.

Abbreviations: FFA, free fatty acids; PAI, plasminogen activator inhibitor I; MI, miocardial infarction.

19-fold increased IL-6 and CRP concentrations, respectively (Table 5). At the same time, the diabetic patients had more pronounced changes in the levels of inflammation markers: IL-6 and CRP concentrations were 5.3-fold and 26-fold higher, respectively (Table 3). At day 12, IL-6 and CRP concentrations had decreased in both groups, but were still on average 2.4-fold (IL-6) and 12.5-fold (CRP) higher than those in the controls, the diabetic MI patients having higher IL-6 and CRP levels during the entire follow-up period.

Correlation analysis demonstrated the correlations between CRP and FFA concentrations $(R=0.53, P=0.04$ for the nondiabetic patients; $R=0.41, P=0.03$ for the diabetic patients) (Figure 1); CRP levels and CK MB activity $(R=0.42$, $P=0.03$ for the nondiabetic patients; $R=0.38, P=0.027$ for the diabetic patients). The diabetic MI patients had a positive correlation between CRP and PAI-1 concentrations $(R=0.5$, $P=0.0027)$ and a negative one with QUICKI $(R=-0.33$, $P=0.039)$. A correlation between basal glucose and IL-6 levels $(R=0.48, P=0.031$ for the nondiabetic patients; $R=0.51, P=0.023$ for the diabetic patients) (Figure 2) and correlations between CRP and postprandial glucose levels were found ( $R=0.48, P=0.045$ for the nondiabetic patients; $R=0.51, P=0.041$ for the diabetic patients) (Figure 3).

In both groups, there were positive correlations between IL-6 and FFA concentrations $(R=0.12, P=0.01 ; R=0.49$, $P=0.005)$, IL-6 and PAI-1 concentrations $(R=0.47$, $P=0.04 ; R=0.54, P=0.03$ ) (Figure 4), IL-6 levels and CK MB activity $(R=0.38, P=0.01 ; \mathrm{R}=0.56, P=0.001)$ (Figure 5), and CRP concentrations and IL-6 levels ( $R=0.29$, $P=0.04 ; R=0.38, P=0.03$ ) (Figure 6).

\section{Discussion}

According to the contemporary understanding, IR has been traditionally regarded as the key stage of T2DM pathogenesis as well as a risk factor for atherosclerosis and MI. ${ }^{15}$ The well-established IR markers are glucose, insulin, and C-peptide concentrations; however, according to medical literature, postprandial insulin and C-peptide levels are more informative than basal (fasting) ones, particularly when there are no obvious IR signs. ${ }^{16}$ This study shows that IR develops in MI patients, which is reflected by basal and postprandial hyperglycemia both in the acute and early recovery phases irrespective of T2DM presence. Indeed, the study demonstrated that both diabetic and nondiabetic patients had significantly increased glucose levels, while basal insulin concentrations did not differ significantly; however, there was a significant 1.7-fold increase in postprandial insulin levels compared to those in the control groups, and the medical literature confirms that this parameter is a marker of IR. IR was also confirmed by lower QUICKI values. Diabetic MI patients had severe IR, and those without T2DM had moderate IR.

Among other IR factors in MI, such proinflammatory cytokines and acute-phase proteins as IL- 6 and CRP have been extensively studied in the medical literature. ${ }^{3}$ Recent research has shown that IL-6 has autocrine and paracrine properties along with its proinflammatory and cardiodepressive effects, and might be involved in IR development in MI patients. ${ }^{17}$ A large prospective trial in 7735 nondiabetic males with no prediabetic conditions, conducted in the UK between 1978 and 2005, showed a strong association between higher IL-6 levels and a risk of T2DM, irrespective of age and obesity. ${ }^{18}$

Table 5 Contents of interleukin 6, C-reactive protein in patients with myocardial infarction on the Ist and I2th day of hospitalization

\begin{tabular}{|c|c|c|c|c|c|}
\hline \multirow[t]{2}{*}{ Variables } & \multirow[t]{2}{*}{ Control $(n=30)$} & \multicolumn{2}{|c|}{ Patients with MI $(n=95)$} & \multicolumn{2}{|c|}{$\begin{array}{l}\text { Patients with } M I \text { and type } 2 \text { diabetes } \\
\text { mellitus }(n=60)\end{array}$} \\
\hline & & I-st day & 12-th day & I-st day & 12-th day \\
\hline Interleukin-6, pg/mL & $3.7(2.8 ; 4.1)$ & $16.25(10.17 ; 24.80)^{*}$ & $9.60(3.0 I ; \mid 4.22)^{* *}$ & $19.43(12.45 ; 25.50)^{* \#}$ & $9.94(7.60 ; \mid 4.60)^{* * *}$ \\
\hline C-reactive protein, $\mathrm{mg} / \mathrm{L}$ & I.I5 (0.86;2.I) & $20.47(9.59 ; 45.85)^{*}$ & $12.99(9.89 ; 14.9)^{* *}$ & $29.86(27.3 ; 31.9)^{* \#}$ & I5.7I $(|2.3 ;| 7.3)^{* *}$ \\
\hline
\end{tabular}

Notes: *compared with control, $(P<0.05)$; **reliable differences in indicators I-st and I2-th day, $(P<0.05)$; ${ }^{*}$ reliable differences among patients with MI with type 2 diabetes and without type 2 diabetes mellitus, $(P<0.05)$. Abbreviation: MI, miocardial infarction. 
$F F A=1.3336+0.083^{*} x$

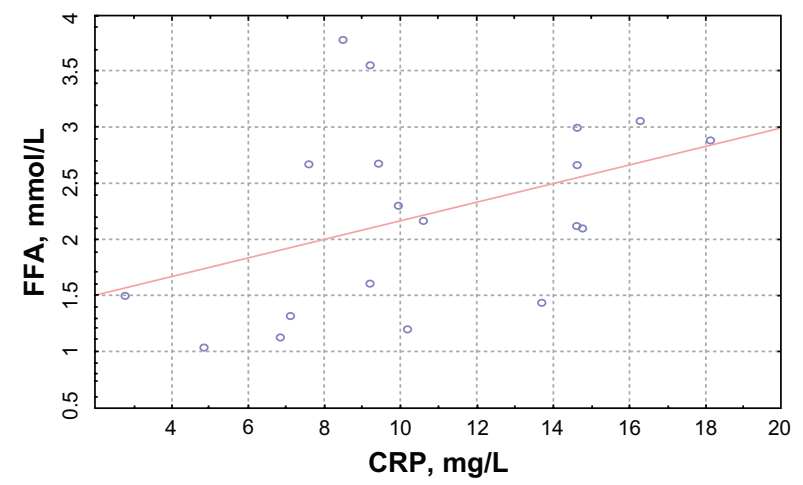

Figure I Correlation between C-reactive protein (CRP) levels and free fatty acids (FFA).

Some authors suggest that molecular mechanisms of mediated IL-6 resistance to insulin might include the activation of proinflammatory serine/threonine stress kinases, protein suppressors of cytokine signaling, and protein tyrosine phosphatases acting as physiologic negative regulators of insulin. ${ }^{2}$

IL-6 was also shown to increase FFA levels in the blood of male volunteers, which could induce resistance to peripheral tissue insulin. IL-6 is supposed to inhibit the activity of lipoprotein lipase in adipocytes, and on the contrary activate cyclic adenosine monophosphate-dependent hormonesensitive lipase in hepatocytes, which contributes to impaired circulating lipoprotein metabolism and FFA buildup inducing insulin-receptor dysfunction and IR development. ${ }^{15,19}$

The results of this study demonstrate higher IL- 6 and FFA levels in the acute phase of MI and their further decrease in the early recovery period. Additionally, at day 1 , the diabetic MI patients had the highest IL-6 and FFA concentrations, which could have been associated with profound metabolic changes due to more pronounced IR in this category of

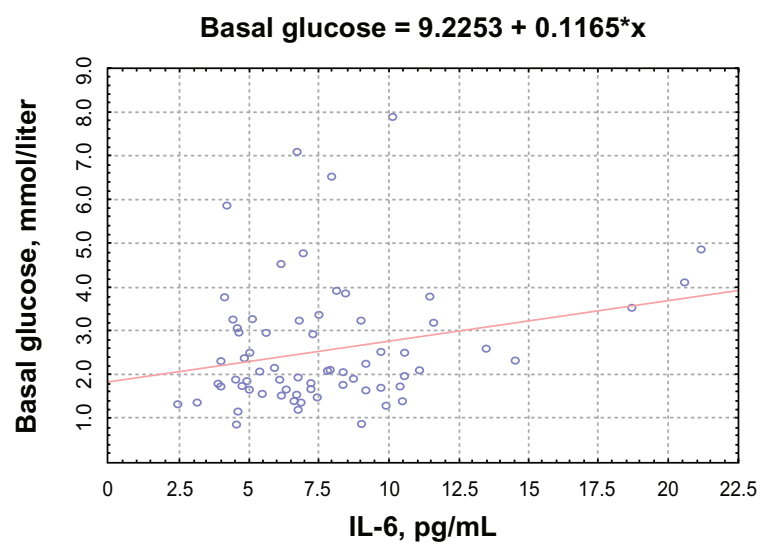

Figure 2 Correlation between basal levels of glucose and interleukin (IL)-6.

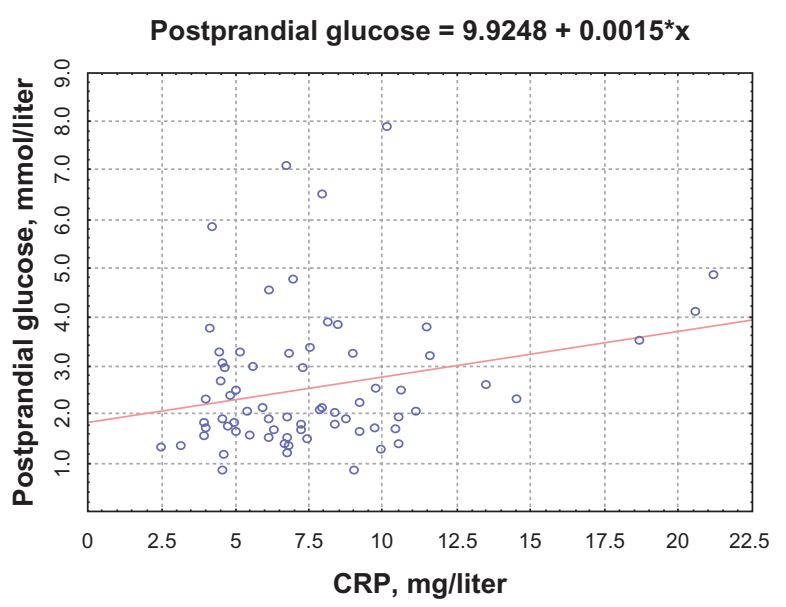

Figure 3 Correlation between C-reactive protein (CRP) levels and postprandial levels of glucose.

patients. The increased production of inflammation mediators seems to contribute to lipolysis activation accompanied by excess FFA release into the blood flow. The observed positive correlation between IL- 6 and FFA levels confirms this suggestion. Reaching the liver, FFA on one hand becomes a substrate for triglyceride and atherogenic lipoprotein production, and on the other hand causes the buildup of other lipid metabolites (ceramides, diacylglycerides), inducing impaired insulin signaling and thereby contributing to IR development to a much greater extent. ${ }^{16}$

According to reports of other authors, IL-6 is produced by different immune-system and adipose-tissue cells, as well as endothelial and epithelial cells. ${ }^{18}$ Experimental studies showed that in MI, the main source of this cytokine is cardiomyocytes, activated macrophages, and T-lymphocytes being attracted to the ischemic region of necrosis. ${ }^{20}$ Obviously, the increase in IL-6 concentrations demonstrates not only higher cytokine production in the cells involved in MI

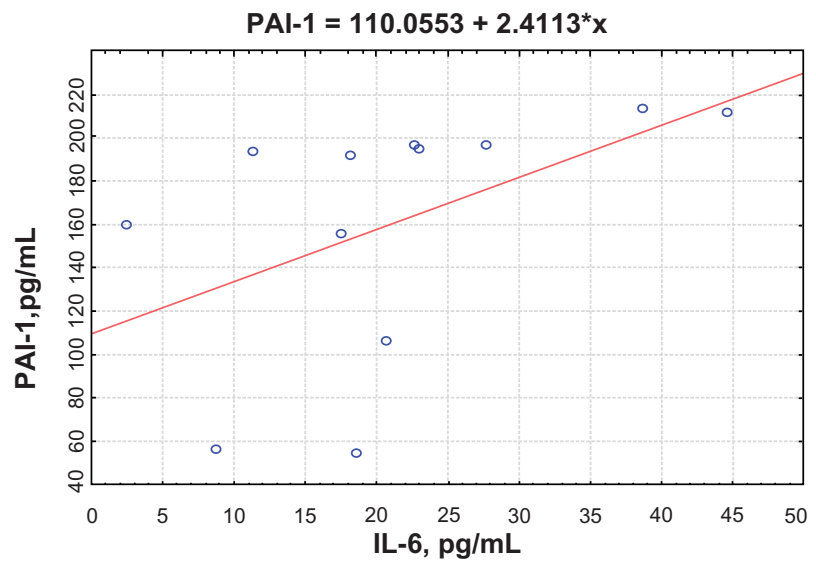

Figure 4 Correlation between plasminogen-activator inhibitor (PAI)-I and interleukin (IL)-6. 


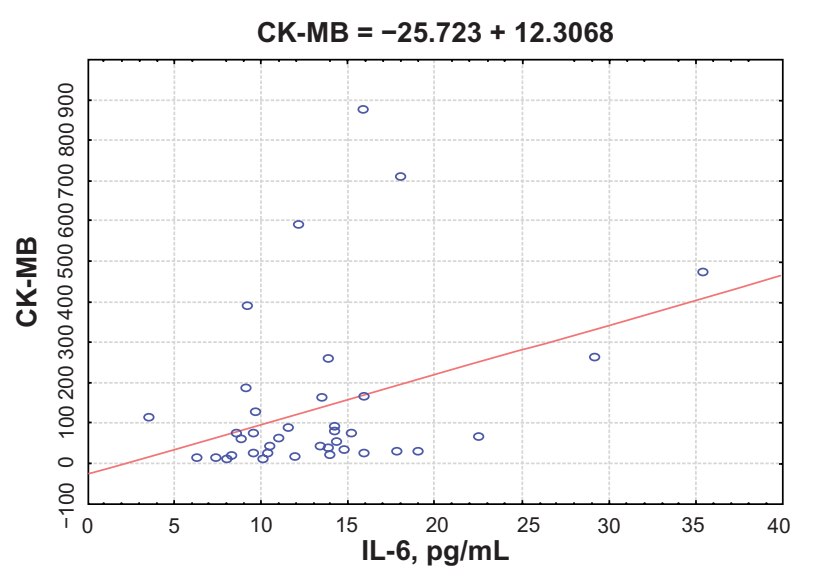

Figure 5 Correlation between interleukin (IL)- 6 levels and creatine kinase (CK) $\mathrm{MB}$ activity.

pathogenesis but also reflects the activity of inflammation in the affected myocardium. The results of the correlation analysis, which showed positive correlations between IL-6 and cardiospecific markers of myocardial necrosis, support this hypothesis.

IL-6 has recently been established to be capable of stimulating PAI-1 in vitro generation in different cells; PAI- 1 is not only the key component of the fibrinolytic system but also an IR marker. ${ }^{11}$ PAI-1 has recently been found to block insulin signaling in adipocytes, and at the same time the exposition of high insulin-content adipocytes was accompanied by increased PAI-1 concentrations in these cells. In this study, we found higher PAI-1 concentrations in both patient groups, and T2DM presence determined higher concentrations of this marker in the acute MI phase.

Meanwhile, in the early recovery phase, both patient groups had lower PAI-1 concentrations, which demonstrated fibrinolytic activity normalization due to the treatment. The correlation analysis showed a positive correlation between IL-6 and PAI-1 concentrations in MI patients, which confirmed the IL-6-inducing impact on the production of this

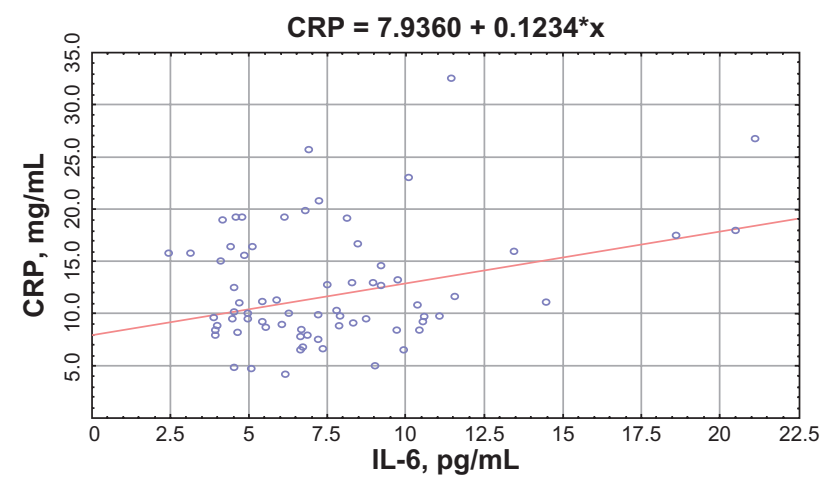

Figure 6 Correlation between C-reactive protein (CRP) levels and interleukin (IL)-6. protein. Obviously, in MI, excess PAI-1 not only leads to slower fibrinolysis, buildup of fibrin, and its degradation products and thereby to microvascular thromboses but is also involved in IR development, which amplifies prothrombotic status. ${ }^{3}$

Along with activated cytokine production, cardiomyocyte ischemia and necrosis are accompanied by the production of acute-phase proteins, primarily CRP, which is involved in the responses aimed at localizing the affected region and myocardial remodeling initiation. ${ }^{16} \mathrm{CRP}$ levels are known to increase significantly already $6-8$ hours after myocardial tissue injury, reach their peak within 24-48 hours, and then decrease with a circulation half-time of 6 hours. ${ }^{17}$ This study shows higher CRP concentrations in both patient groups in the acute and early recovery phases. The presence of T2DM determined the highest protein concentrations in MI patients during the entire follow-up period, which might be associated with higher IL-6 concentrations in this patient category. Previous research has established IL-6 to be the most significant inducer of CRP production. At the same time, experimental studies showed that CRP was capable of inducing IR. According to Pravenec et al, transgenic rats expressing human CRP in high concentrations had metabolic disorders (hyperinsulinemia, hyperglycemia, and glycogen-production impairment stimulated by insulin in the skeletal muscles), which are intrinsic to IR syndrome. ${ }^{21} \mathrm{D}^{\prime}$ Alessandris et al established that CRP induces serine phosphorylation in the insulin-receptor domain, which impairs the ability of the latter to activate phosphatidylinositol 3-kinase and leads to IR development in rat myocytes. ${ }^{22}$ Meanwhile, we discovered positive correlations between CRP levels and the activity of CK MB fraction. The observed correlative associations between CRP and metabolic IR markers demonstrate that IL-6 is not only the key inflammation mediator but also plays an active role in FFA and glucose metabolism, and fibrinolytic system protein production and secretion, which can be involved in pathogenetic events associated with IR in MI.

\section{Conclusion}

The results of this study demonstrate that MI as well as activated inflammation is accompanied by IR development. The most informative indicators of impaired sensitivity to insulin in MI are increases in FFA and PAI-1 levels compared to postprandial glycemia and insulinemia. The observed strong associations between IL-6, CRP, basal and postprandial glycemia, and insulinemia, as well as FFA and PAI-1 levels evidence the involvement of nonspecific inflammation factors 
in IR development and the amplification of prothrombogenic potential in MI patients.

In turn, the presence of preexisting IR determines higher thrombogenic status and increases the risk of not only primary but also recurrent cardiovascular events. The observed consistent patterns can lead to new treatment strategies to prevent T2DM in MI patients and improve quality of life.

\section{Acknowledgment}

The authors wish to thank Anna Bashkireva for her assistance in writing this article.

\section{Disclosure}

The authors report no conflicts of interest in this work.

\section{References}

1. Pickup J. Inflammation and activated innate immunity in the pathogenesis of type 2 diabetes. Diabetes Care. 2004;27:813-823.

2. Yu Q, Gao F, Ma XL. Insulin says NO to cardiovascular disease. Cardiovasc Res. 2011;89:516-524.

3. Fernández JM, Rilcart W. Insulin resistance and chronic cardiovascular inflammatory syndrome. Endocr Rev. 2003;24:278-301.

4. Smit JW, Romijn JA. Acute insulin resistance in myocardial ischemia: causes and consequences. Semin Cardiothorac Vasc Anesth. 2006;10: 215-219.

5. Antoinette M, Steffen L, Jacobs D,et al. Relation of C-reactive protein to insulin resistance and cardiovascular risk factors in youth. Diabetes Care. 2005;28:1763-1768.

6. Barrett TD, Hennan JK, Marks RM, Lucchesi BR. C-reactive-proteinassociated increase in myocardial infarct size after ischemia/reperfusion. J Pharmacol Exp Ther. 2002;303:1007-1013.

7. Fernandez-Real JM, Vayreda M, Richart C, et al. Circulating interleukin 6 levels, blood pressure, and insulin sensitivity in apparently healthy men and women. $J$ Clin Endocrinol Metab. 2001;86:1154-1159.

8. Geiger PC, Hancock C, Wright DC, Han DH, Holloszy JO. IL-6 increases muscle insulin sensitivity only at superphysiological levels. Am J Physiol Endocrinol Metab. 2007;292:1842-1846.
9. Frangogiannis NG, Smith CW, Entman ML. The inflammatory response in myocardial infarction. Cardiovasc Res. 2002;53:31-47.

10. Collet JP, Montalescot G, Vicaut E, et al. Acute release of plasminogen activator inhibitor-1 in ST-segment elevation myocardial infarction predicts mortality. Circulation. 2003;108:391-394.

11. Alessi MC, Juhan-Vague I. PAI-1 and the metabolic syndrome. Arterioscler Thromb Vasc Biol. 2006;26:2200-2207.

12. Juhan-Vague I, Morange PE, Frere C, et al. The plasminogen activator inhibitor-1 - 675 4G/5G genotype influences the risk of myocardial infarction associated with elevated plasma proinsulin/insulin levels in men from Europe: the HIFMECH study. J Thromb Haemost. 2003;1: 2322-2329.

13. Kryzhanovsky VA. Diagnosis and treatment of myocardial infarction. K.: Phoenix; 2001.

14. Katz A, Nambi SS, Mather K, et al. Quantitative insulin sensitivity check index: a simple, accurate method for assessing insulin sensitivity in humans. J Clin Endocrinol Metab. 2000;85:2402-2410.

15. Leclercq IA, Da Silva Morais A, Schroyen B, Van Hul N, Geerts A. Insulin resistance in hepatocytes and sinusoidal liver cells: mechanisms and consequences. $J$ Hepatol. 2007;47:142-156.

16. Cefalu WT. Insulin resistance: cellular and clinical concepts. Exp Biol Med (Maywood). 2001;226:13-26.

17. Papanicolaou DA, Vgontzas AN. Interleukin-6: the endocrine cytokine. J Clin Endocrinol Metab. 2000;85:1331-1333.

18. Nieto-Vazquez I, Fernández-Veledo S, de Alvaro C, Lorenzo M. Dual role of interleukin-6 in regulating insulin sensitivity in murine skeletal muscle. Diabetes. 2008;57:3211-3221.

19. Opie LH, Knuuti J. The adrenergic-fatty acid load in heat failure. $J \mathrm{Am}$ Coll Cardiol. 2009;54:1637-1646.

20. Gwechenberger M, Mendoza LH, Youker KA, et al. Cardiac myocytes produce interleukin- 6 in culture and in viable border zone of reperfused infarctions circulation. Circulation. 1999;99:546-551.

21. Pravenec M, Kajiya T, Zídek V, et al. Effects of human C-reactive protein on pathogenesis of features of the metabolic syndrome. Hypertension. 2011;57:731-737.

22. D'Alessandris C, Lauro R, Presta I, Sesti G. C-reactive protein induces phosphorylation of insulin receptor substrate-1 on Ser ${ }^{307}$ and Ser $^{612}$ in L6 myocytes, thereby impairing the insulin signalling pathway that promotes glucose transport. Diabetologia. 2007;50:840-849.
Journal of Inflammation Research

\section{Publish your work in this journal}

The Journal of Inflammation Research is an international, peer-reviewed open-access journal that welcomes laboratory and clinical findings on the molecular basis, cell biology and pharmacology of inflammation including original research, reviews, symposium reports, hypothesis formation and commentaries on: acute/chronic inflammation; mediators of inflamma-

\section{Dovepress}

tion; cellular processes; molecular mechanisms; pharmacology and novel anti-inflammatory drugs; clinical conditions involving inflammation. The manuscript management system is completely online and includes a very quick and fair peer-review system. Visit http://www.dovepress.com/ testimonials.php to read real quotes from published authors. 